\title{
HIPERTEXTO: A FORMAÇÃO DE UM LEITOR COMO AUTOR
}

\author{
HYPERTEXT: READER FORMATION AS AUTHOR
}

\section{HIPERTEXTO: LA FORMACIÓN DE UN LECTOR COMO AUTOR}

JEAN Custódio de LimA ${ }^{\mathrm{I}}$

Dagoberto Buim ArenA ${ }^{\text {II }}$

Resumo Este artigo trata do uso de hipertextos na formação de leitores/autores. Assim sendo, ele objetiva discutir mudanças do conceito de autoria diante desse novo formato de ler e aprender, oriundo do advento da internet e de seu impacto na educação. Por intermédio de uma pesquisa bibliográfica, observa-se que, pelo processo de leitura não-linear, no qual o estudante tem acesso ilimitado a outros textos de acordo com a sua escolha, o aluno é um autor em potencial, pois essa forma de leitura detém uma significativa diferença entre os textos impressos, visto que é dinâmico e flexível devido às possibilidades dos links e do diálogo com outras interfaces semióticas, permitindo, assim, a construção de um texto único e original. Desse modo, com o apoio do professor em uma atividade epilinguística vinculada à tecnologia, pode-se fazer do aluno um leitor/autor mais maduro. Enfim, embora o ensino da linguagem tenha se reduzido simplesmente às nomenclaturas, ao estudo sintático e às classificações, conclui-se que o uso das TIC, com sua vasta intertextualidade e dialogia semiótica, pode ajudar a reverter essa constatação.

Palavras-chave: Hipertexto; Epilinguística; Formação de leitores/autores.

Abstract This article deals with the use of hypertexts on readers/authors formation. Therefore, its objective is to discuss changes of authorship concept before this new internet reading and learning format and its impact on education. Through a bibliographical research, it is observed that using such a non-linear reading process in which student has unlimited access to other texts according to his choices, learner is a potential author because

'Instituto Federal de Educação, Ciência e Tecnologia do Ceará - IFCE Campus Fortaleza

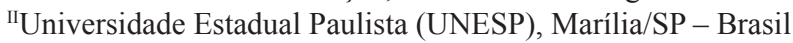


hypertexts differ significantly from printed texts since they are dynamical and flexible due to links possibilities and dialogues with other semiotic interfaces, allowing a unique and original text construction. Then, with teacher support on an epilinguistic activity and technology use, it is possible to have a more mature reader/author. Finally, although language teaching has been reduced merely to terminology, to syntactic analysis and to classification, it is concluded that TIC use along with its vast intertextuality and semiotic dialogue may help to change that fact.

Key-words: HyperteXts; Epilinguistic; ReAders/Authors Formation.

Resumen Este artículo se refiere al uso de hipertextos en la formación de lectores/autores. De este modo, este trabajo tiene como objetivo discutir los cambios de concepto de autoría delante de ese nuevo formato de leer y aprender, procedente del advenimiento de la internet y de su impacto en la educación. A través de una investigación bibliográfica, se observa que, por medio de un proceso de lectura no lineal, en el cual el estudiante tiene acceso ilimitado a otros textos de acuerdo con sus elecciones, el alumno es un autor potencial, pues ese modo de lectura detiene una significativa diferencia entre los textos impresos, ya que es dinámico y flexible debido a las posibilidades de links o enlaces y del diálogo con otras interfaces semióticas, permitiendo, así, la construcción de un texto único y original. Así, con el apoyo del profesor en una actividad epilinguística, vinculada a la tecnología, se puede hacer del alumno un lector/autor más maduro. Por último, aunque la enseñanza del lenguaje se haya reducido simplemente a nomenclaturas, al estudio sintáctico y a las clasificaciones, se concluye que el uso de la TIC, con su amplia intertextualidad y dialógica semiótica, puede ayudar a revertir esa constatación.

Palabras clave: Hipertexto; Epilinguística; Formación de lectores/autores.

\section{INTRODUÇÃo}

As mudanças sociais não só romperam fronteiras pela desterritorialização do sujeito e do saber, como também produziram o desgaste da distinção entre culturas, rompendo, assim, as fronteiras linguísticas no que tange à função-autor. - FOUCAULT, 1992

Vive-se numa sociedade da aprendizagem e de um enorme fluxo de informação. Pode-se observar que há uma demanda muito grande por conhecimento no mercado de trabalho contemporâneo, exigindo dos alunos uma formação constante e uma recapacitação profissional que atinge a todos os meios produtivos. Por isso, esse é um mercado de trabalho difícil de entender, mutável, flexível e imprevisível, com um rápido ritmo de mudanças tecnológicas que nos obrigam a estar sempre aprendendo. Porém, não se pode esquecer que, mesmo dentro do contexto apresentado, deve haver também uma preocupação, por parte de educadores, com uma formação integral de um indivíduo que seja crítico e que vise uma sociedade mais humana. Ou seja, é papel crucial do professor nesse milênio ajudar o aluno a transformar informação em conhecimento útil para a construção de uma cidadania digna. 
A educação, em todos os níveis, por essas razões, é alvo recente de preocupações, debates e investimentos por parte de governos, empresários e da sociedade em geral, visto que, atualmente, discute-se a importância de se repensar algumas práticas pedagógicas para enfrentar os desafios advindos da globalização, da revolução das mídias de comunicação e informação e do encaminhamento para uma sociedade interdependente. Ao discorrer sobre o impacto das Tecnologias da Informação e Comunicação, doravante TIC, Pallof e Pratt (1999, p. 3) defendem que:

As instituições acadêmicas de hoje estão em transição. A grande parte destas mudanças que estamos presenciando hoje é devida às pressões mercadológicas em busca de menores custos e também devido à demanda do mundo corporativo por profissionais que funcionem bem em uma sociedade pautada no conhecimento e na informação.

Deve-se ressaltar ainda que, segundo a empresa Ibope Media (2015), há aproximadamente 120 milhões de internautas no país, sendo o Brasil o quinto país mais conectado. Ainda de acordo com esses dados, o percentual de brasileiros conectados à internet aumentou de $27 \%$ para $58 \%$, entre 2007 e 2015 . Não se pode deixar de mencionar também que as TIC já estão presentes em $75 \%$ das escolas públicas urbanas e $13 \%$ das rurais. Outra informação importante para a argumentação neste artigo, que visa contribuir não somente para o entendimento desse novo panorama, mas também para a discussão de uma educação pública de qualidade para as gerações seguintes, é a entrada da classe $\mathrm{C}$ em massa para o clube dos internautas. Sabe-se que, sem nenhuma tentativa de fazer apologia a governos, esse crescimento é um fato real, devido aos programas sociais e à melhoria da economia na primeira década do século, que entre outros benefícios, possibilitou o acesso dos mais pobres a toda uma gama de dispositivos eletrônicos e, portanto, o acesso à informação. Isso permitiu, mesmo ainda que de forma modesta, que parte da população antes excluída, também participasse desse novo mundo tecnológico.

Portanto, com o advento do computador e o crescente apelo tecnológico do final do século XX e início deste século, aspectos nunca considerados como perfil dos aprendizes e professores, relações interpessoais, estilos e estratégias de aprendizagem e, principalmente, o uso de recursos multimídias nos contextos de ensino de língua portuguesa, acabaram por encontrar espaço para estudos e investigações. Desse modo, como resultado dessa nova ordem, da qual as TIC fazem parte do dia a dia de alunos e professores, e em que há também a existência de uma expectativa distinta em relação à escola, pode-se observar que esses dispositivos, mesmo com algumas reservas, estão paulatinamente sendo incorporados ao chão da escola e à educação de forma generalizada, apresentando para a sociedade, via internet, um novo formato de texto e um novo perfil de leitor.

Assim, deve-se frisar ainda que é criada uma nova forma de construir conhecimento por meio de um processo de leitura diferenciado, pois o aluno, ao enfrentar esses textos não-lineares, passa a ter mais controle (com a supervisão do professor) sobre sua própria aprendizagem, visto que essa nova modalidade de textos, com suas características pecu- 
liares, pode possibilitar ao leitor contemporâneo participação ativa na construção de sua formação com a prática desse modo de leitura.

Esse formato designa uma coleção de documentos com links ou hiperlinks, que auxiliam o aluno a ir de um texto a outro, em um movimento autogerenciado, isto é, o aprendiz tem liberdade de fazer escolhas durante o processo de leitura, aprofundando-se mais em um tópico que em outro, construindo, dessa maneira, com o apoio de seu professor e de uma gama de mídias como imagem e som, um texto único e com marcas de autoria. Ademais, com a incorporação dessas novas tecnologias à sala de aula, o professor de língua portuguesa pode, na tentativa de diminuir a defasagem dos alunos no domínio de sua língua materna, abrir espaço para práticas nas quais o aprendiz torne-se um leitor melhor por meio da experiência com esses textos virtuais desde o ensino fundamental com o objetivo de sanar um problema grave, visto que o país ocupa a posição $55^{\mathrm{a}}$. no ranking de leitura de acordo com o site UOL Educação (2014), abaixo de países como Chile, Uruguai, Romênia e Tailândia. Ainda de acordo com esses dados do Programme for International Student Assessment (Pisa), metade dos alunos brasileiros não consegue alcançar o nível 2 de desempenho em leitura, no qual o teto da escala é 6. Isto é, esses jovens são incapazes de deduzir informações, estabelecer relações e compreender nuanças mais complexas presentes nos textos.

Logo, o uso das TIC, com a possibilidade de empoderar e de dar mais autonomia ao estudante durante o processo de aprendizagem, pode, por causa desses aspectos, apresentar-se também como uma oportunidade de motivá-los, já que além de pôr o aluno em sintonia com o seu tempo, ao permitir o acesso a elas, a escola também pode formar um cidadão mais atuante, capaz de propor intervenções críticas diante de suas relações com a sua comunidade e com o mundo, haja vista que terá uma maior compreensão da cibercultura já presente em sua vida. Na verdade, ao expor o aluno a uma gama infinita de textos e de toda a informação produzida, a escola, responsável maior pela alfabetização, recupera, pelo desenvolvimento e ensino dos atos de ler, as intenções da enunciação desses documentos, inserindo esse indivíduo na cultura, possibilitando a ele apropriar-se do passado, pensar o agora e dando-lhe o poder de agir (protagonismo) sobre o que virá (BREVES, 2004). A esse respeito também, Orlandi (2001, p. 15 apud FISTAROL e SCHONS, 2015) afirma que:

\footnotetext{
A mediação, ocasionada pelo discurso, possibilita ao sujeito ser inserido na sociedade, conseguindo assim deslocar-se e transformar-se, habituando-se ao meio em que vive; por isso, o discurso torna-se indispensável para a comunicação e a evolução humana, mas não podemos esquecer que tudo isso acontece através da linguagem.
}

Assim sendo, este artigo tem por objetivo discutir as possíveis mudanças do conceito de autoria diante desse formato de ler e aprender, oriundo do advento da internet e de seu impacto na formação de leitores como autores. 


\section{O LEITOR COMO AUTOR EM HIPERTEXTOS}

Nesta seção, destaca-se o papel do hipertexto na formação de um aluno leitor/autor, pois esse formato designa um processo de leitura não-linear e não hierarquizado, que permite $o$ acesso ilimitado a outros textos de forma instantânea e de acordo com a escolha do usuário, por meio de todos os aportes sígnicos disponibilizados pela cultura digital, fazendo de cada aluno um autor em potencial, porque esse modo de leitura detém uma significativa diferença entre os textos impressos, visto que é dinâmico e flexível devido às possibilidades dos links, os quais fazem elos com outras páginas e estabelecem um diálogo com outras interfaces semióticas, permitindo, assim, a construção de um texto único e original (XAVIER, 2004).

Esse inusitado processo de leitura, que traz em si a coparticipação, a coautoria do leitor durante o próprio ato de leitura na construção simultânea do texto abordado pelo leitor, permite ao aluno construir o seu caminho no processo de caminhar, isto é, torna-o responsável não somente pela coescrita do texto, mas, diferente do ensino tradicional, no qual o professor configura-se como detentor absoluto do conhecimento, faz dele responsável também pela condução de seu próprio aprendizado. A esse respeito, Komesu (2005, p. 97) afirma que:

O hipertexto é uma forma de organização cognitiva e referencial cujos princípios constituem um conjunto de possibilidades estruturais que caracterizam ações e decisões cognitivas baseadas em (séries de) referenciações não contínuas e não progressivas. Considerando que a linearidade linguística sempre constituiu um princípio básico da teorização (formal ou funcional) da língua, o hipertexto rompe esse padrão em alguns níveis. Nele, não se observa uma ordem de "construção", mas possibilidades de autoria textual plurinearizada.

Diante dessa realidade cabem, sobre essa questão, algumas considerações acerca do perfil desse novo aluno, que deve ser levado pelo professor a ser protagonista na construção de saberes tão necessários à sua formação como um leitor/autor pleno. Exige-se desse aprendiz, primeiramente, um razoável domínio do sistema linguístico e também um bom conhecimento dos diversos gêneros textuais atuais para que ele possa compreender e interpretar textos das mais variadas complexidades, com o objetivo de internalizar esses conhecimentos, tornando-se capaz de dizer algo (plano do conteúdo) de forma única (plano da expressão) (HJELMSLEV, 1975), e isso só pode acontecer dentro de um ambiente democrático, ou seja, a escola também deve estar preparada para administrar essa inovação sem autoritarismo e sem controle excessivo desde as séries iniciais.

Outra observação importante, quando se trata do perfil desse estudante, é a sua capacidade, em razão das inúmeras escolhas possíveis, de não perder a noção de coerência e topicidade para evitar, assim, a divagação infrutífera em outros textos, que não apresentam relação alguma com o tópico de partida. Isto é, ele deve ser capaz de recuperar as teses, os princípios, instituindo relações lógico-discursivas durante a sua seleção textual, para ir construindo com elas, mesmo que de forma fragmentada, um texto único e com sentidos amplos, recuperando, desse modo, as primeiras intenções comunicativas do autor, mas atri- 
buindo a elas novos valores, os dele, como leitor e autor que se torna ao ler. A respeito dessa questão, Marcuschi (1999, p. 33 citado por KOMESU, 2005, p. 7) alerta:

[...] Como consequência das complexas ligações hipertextuais, a perda das noções de coerência e de topicidade. Podem existir adições, divisões, inserções, substituições, derivações, disjunções que comprometem a continuidade temática e a progressão referencial.

Desse modo, exige-se, ainda, quando se trata de autoria nessa conjuntura, que esses textos dos alunos apresentem as marcas de quem os produz, nas escolhas e na análise que se faz da realidade, evitando assim cópias de opiniões prontas de outrem e a prática tão conhecida atualmente de copiar e colar, buscando-se como fim, a construção, pelos alunos, de suas próprias interpretações dos fatos observados e da criação individual de suas próprias cosmovisões, como defendem Platão e Fiorin (1990, p. 360): "A personalização que se requer em cada texto é aquela que se reflete no modo de encaminhar o raciocínio, na maneira diferenciada de organizar os dados, de utilizar a linguagem".

Logo, diante do cenário que se apresenta no país e diante da presença marcante do mundo virtual na vida de jovens estudantes, principalmente oriundos de escolas das redes estaduais e municipais de ensino, cremos ser possível viabilizar, com mais celeridade e engajamento, a construção desse texto autoral com a participação efetiva de um professor preparado. Por sua vez, a formação de leitores como autores pelo hipertexto não se apresenta como solução última para resolver as questões do ensino de língua portuguesa no Brasil, pois são conhecidas as suas carências e a má formação inicial de professores que, por vezes, desconhecem a natureza, os processos cognitivos envolvidos e os fundamentos básicos de como as crianças e os jovens aprendem, conforme as teorias mais divulgadas. De fato, essa propositura constitui somente uma alternativa, aplicada quando possível, de tentar melhorar o desempenho do aluno como leitor e de formá-lo como cidadão consciente, mais participante na sociedade globalizada contemporânea.

\section{Papel do Professor no ensino de língua PORTUGuesa E NA FORMaÇão do LEITOR COMO AUTOR EM HIPERTEXTOS}

Face ao cenário já apresentado, é possível defender o princípio de que os professores devam fazer uso frequente das TIC em sala de aula e fora dela, com o objetivo de otimizar todas as potencialidades que esse novo meio agrega ao ensino, ao uso da linguagem e, por fim, à formação desse leitor como autor. No que concerne ao uso dos alunos nesse novo meio, Magnabosco (2009, p. 56) enfatiza que:

\footnotetext{
A Internet pode ser uma grande aliada para resgatar nos alunos as motivações e os estímulos perdidos, pois, além de oferecer muitas possibilidades para um enriquecimento informacional, permite também o resgate de um destinatário real para as produções escolares, o que pode repercutir em um interesse maior na aprendizagem da língua materna.
} 
Esse é um dado importante, visto que as produções textuais dos alunos raramente têm um destino certo, porém, a internet, além de apresentar outras vantagens, pode também suprir essa deficiência, se usada de forma inteligente e ética pelos professores, já que eles têm ao seu alcance um ambiente pleno de possibilidades, com várias ferramentas que permitem criar movimentos dialógicos diversos como chats, redes sociais, blogs, fóruns, e-mails etc.

Desse modo, com a inserção da tecnologia na educação, tornou-se imprescindível a introdução da informática nas redes de ensino, sejam elas públicas ou privadas. Diante desse fato, como já posto, mesmo as escolas públicas, foco deste artigo, têm investido na implantação de salas de informática, ilhas digitais, salas de multimeios ou laboratórios de multimídia, por isso alunos oriundos de classes mais humildes têm o privilégio de chegar a essas instituições dotadas de ambientes mais equipados, atraentes e dinâmicos, que os colocam diante de novos desafios, de novas possibilidades e, principalmente, em contato com o seu tempo, fazendo um resgate desses jovens que não têm, usualmente, acesso a essas novas ferramentas e são, portanto, excluídos e marginalizados socialmente. Conforme Perrenoud (2000, p. 28):

[...] formar para as novas tecnologias como a Internet é formar o julgamento, o senso crítico, o pensamento hipotético e dedutivo, as faculdades de observação e de pesquisa, a imaginação, a capacidade de memorizar e classificar, a leitura e a análise de textos e de imagens, a representação de redes, de procedimentos e de estratégias de comunicação.

Como visto, desenvolver o raciocínio ou possibilitar situações de resolução de problemas é certamente a razão mais nobre e indiscutível do uso do computador na aprendizagem e no desenvolvimento da linguagem com esses recursos tecnológicos. Desse modo, esse processo de ensino e de aprendizagem deve ser percebido, pelo professor, como um processo educativo que envolve meios de comunicação capazes de ultrapassar os limites de tempo e espaço, tornando acessível a interação com as fontes de informação e com o sistema educacional, de forma a promover a independência linguística do aluno, com ações de estudo mais autônomas e flexíveis.

Vale ressaltar ainda que o leitor de hipertexto nasceu em um mundo de leituras extensivas, portanto, não se aproxima do leitor de poucas possibilidades de tempos anteriores e, vale sobrelevar também, que cabe ao professor tirar proveito dessa oportunidade. Ora, há textos em profusão em todos os lugares e suportes. Esses são traços marcantes das sociedades que estão em contato com a escrita e com o texto na contemporaneidade, visto que vivemos inseridos em um sistema de mídias (BRIGGS e BURKE, 2004) onipresente e, por conseguinte, não se deve fechar as portas das escolas para essa realidade.

É importante mencionar ainda que esses usuários do hipertexto têm a liberdade não somente de ler textos, mas a possibilidade de elaborar, construir e reconstruir sentidos e lançar ideias sozinhos ou em cooperação, ou seja, esses eventos possibilitam a escrita coletiva e o compartilhamento de conhecimentos em rede. Enfim, eles podem solucionar problemas de forma cooperativa e virtual. 
Warschauer et al. (2000, p. 7) listam cinco razões principais para o uso da Internet e aplicativos no ensino: 1) contextos autênticos e significativos; 2) aumento de letramento por meio da leitura, escrita e possibilidades de publicação na internet; 3) interação, a melhor forma para se adquirir conhecimento; 4) vitalidade obtida pela comunicação em um meio flexível e multimídia; e 5) empoderamento, pois o domínio das ferramentas da iInternet torna os aprendizes mais autônomos ao longo da vida. Portanto, resta aos professores usar essas ferramentas para formar um leitor mais eficiente, dinâmico e crítico, que seja capaz de fazer as escolhas certas na construção de hipertextos. A partir desse texto virtual, cria-se um novo modelo de comunicação entre o corpo docente e discente. Por essa razão, antes de tudo, o professor deve ser percebido como um parceiro no processo de aprendizagem em vez de ser apenas um mero transmissor de conhecimento, mas que saiba tomar as rédeas para si quando as coisas fugirem ao controle. Dessa forma, o eixo ensino/aprendizagem deixa de ser de mão única no sentido do professor passar conhecimentos para seus alunos que, por sua vez, tinham a obrigação de assimilá-los com dedicação e sem nenhuma crítica. Na verdade, nesse espaço, há a possibilidade maior de existir um ambiente mais democrático, isto é, uma pedagogia mais centrada nas interrogações que faz o aluno a respeito do conhecimento do que nas informações distribuídas pelo professor. Essa é, de fato, uma oportunidade real para dar os primeiros passos na aquisição e desenvolvimento da língua num espaço protegido, democrático, solidário (visto que não há punições no caso de erros) e privilegiado, pois o professor, frequentemente, está ao lado do aluno para ajudá-lo.

Entretanto, isso exige uma participação autêntica por parte de todos, já que o aluno tem voz para fazer suas escolhas. Logo, deve haver um compromisso sério que demanda das partes um perfil diferenciado durante o processo de ensinar e de aprender. E é, talvez, nessa mudança que pode residir todo o sucesso dos textos on-line que despontam pelo mundo. A comunicação nessa nova sala de aula é uma troca onde todos aprendem, inclusive o professor, visto que os alunos dominam, com frequência, a tecnologia melhor do que os próprios mestres. Donato (1994) afirma que esses papéis de parceiro mais experiente e aprendiz não são fixos e podem ser invertidos, dependendo do problema a ser resolvido nesse novo meio.

Dessa maneira, a noção do aluno como responsável, embora o professor esteja disponível para ajudá-lo, pela construção de sua própria leitura, de seu texto por meio da organização da sequência, faz desse processo algo bastante pessoal, pois ele tem a possibilidade de optar entre caminhos diversificados, de modo a permitir diferentes níveis de desenvolvimento e de aprofundamento em um tema escolhido.

Como se pode perceber, a leitura do hipertexto potencializa paulatinamente a emancipação do leitor, visto que a partir dos links o aluno pode seguir por rotas diferentes daquelas originalmente concebidas pelo autor original. Isto é, as opções que se faz através dos nós e dos links quebram o contrato firmado entre autor e leitor para o estabelecimento de um ponto de chegada da leitura do hipertexto. Podemos inferir que, ao interagir com hipertextos, os alunos podem desenvolver habilidades e competências requeridas para esse modo de enunciação digital, como optar por informações relevantes e serem capazes de es- 
tabelecer as relações entre os diversos excertos. Ademais, a leitura não deve ser vista como única, já que por intermédio das escolhas, o aluno se depara com uma diversidade de vozes (intertextualidade), e por meio delas, vai construindo novos significados, ou seja, ao longo do processo, ganha experiências e torna-se autor de seu discurso e de sua aprendizagem.

$\mathrm{O}$ aluno tem um papel mais ativo no seu processo de aprendizagem (mas conta com a ajuda do professor sempre que for necessário), visto que a leitura é a coconstrução de diferentes gêneros como uma atividade na qual a compreensão das estruturas linguísticas se dá através de uma aprendizagem implícita das formas discursivas, com um enfoque epilinguístico, especialmente, para os primeiros anos do ensino fundamental, evitando-se, dessa forma, um empobrecimento da criatividade linguística dos alunos. Ainda sobre essa questão, Miller (2003, p. 1) afirma:

[...] Entendemos por atividade epilinguística o exercício da reflexão sobre o texto lido/escrito e da operação sobre ele a fim de explorá-lo em suas diferentes possibilidades de realização, uma atividade que se diferencia da atividade linguística, essencialmente voltada para o próprio ato de ler e escrever, e da atividade característica do plano metalinguístico que supõe a capacidade de falar sobre a linguagem, descrevê-la e analisá-la como objeto de estudo.

Nessa fase, forçar a criança a ler um livro, sem nenhuma abordagem afetiva, causará somente recusa e desprezo pela leitura. Deve-se, no entanto, tentar seduzir o leitor iniciante com textos que sejam interessantes para ele, pois é pelo debate, pela discussão, pela magia das palavras e da imagem, que o indivíduo torna-se capaz de esboçar sua própria visão de mundo (BREVES, 2004). Deve-se frisar também que esses diferentes gêneros textuais em forma de hipertextos podem ser usados, dada a profusão existente, para discussões metalinguísticas nas séries mais avançadas, pois são uma forma de apresentar a organização discursiva da linguagem de maneira contextualizada a um leitor já mais maduro, com desprezo pela mera memorização de regras gramaticais em frases modelo.

Ora, por muito tempo, a escola somente teve a atenção voltada para os estudos de linguagem nos estreitos limites da variedade linguística de prestígio e de sua gramática para todos os níveis de ensino. Enfim, a atividade epilinguística, vinculada à tecnologia, pode ter um papel muito importante na formação de um leitor/autor desde a mais tenra idade, isto é, esse exercício de reflexão e de operação sobre a língua portuguesa pode fazer da criança um leitor progressivo devido ao processo de revisão e de reformulação continuada do seu texto, em um trabalho de parceria (que não precisa ser monótono ou massacrante) com seu professor e de conscientização dentro das infinitas possibilidades do hipertexto. Em suma, $\mathrm{o}$ ato de ler, de criação de sentidos, não pode ser jamais um fardo sobre os ombros dos professores ou de seus alunos.

É relevante destacar ainda que as diretrizes dos Parâmetros Curriculares Nacionais (PCNs, p. 23) entendem o texto, em suas inúmeras possibilidades de gênero, como elemento basilar das discussões em detrimento de um estudo gramatical, que só distanciaria ainda mais os alunos da competência discursiva, ou seja, do uso cultural e social da linguagem 
nas suas mais variadas funções e como elemento de construção de cidadania. Nessa linha de pensamento, segundo as diretrizes dos PCNs:

[...] Tomando-se a linguagem como atividade discursiva, o texto como unidade de ensino e a noção de gramática como relativa ao conhecimento que o falante tem de sua linguagem, as atividades curriculares em Língua Portuguesa correspondem, principalmente, a atividades discursivas: Uma prática constante de escuta de textos orais, leitura de textos escritos e de produção de textos orais e escritos, que devem permitir, por meio da análise e reflexão sobre os múltiplos aspectos envolvidos, a expansão e construção de instrumentos que permitam ao aluno, progressivamente, ampliar sua competência discursiva.

Enfim, este presente artigo pretende ainda refletir acerca das possibilidades educativas da internet quanto à leitura e autoria textual, isto é, repensar a sua prática pedagógica, porque a tecnologia per se não desempenha uma função catalítica, pois cabe ao professor de língua portuguesa preparar esse leitor/autor não somente para lidar com essas tecnologias, mas também para conhecer minimamente as manifestações múltiplas de seu idioma, no intuito de alterar o desempenho indicado pelo resultado da prova do ENEM de 2014, na qual mais de 500 mil jovens obtiveram a nota zero em redação (TELES, 2015). Apesar de se tratar de indicações de desempenho em atos de escrita, é possível estabelecer relações com o desempenho também frágil em atos de leitura.

De fato, é o uso que fazemos desses aparatos tecnológicos que pode favorecer o processo de construção, ou seja, o processo de formação dos alunos, de permitir a criação da autoria pelo discurso do sujeito aprendente, para que a voz do professor não seja (embora o aluno necessite de sua ajuda), eternamente, a única a ecoar na sala de aula e para que o aluno esteja preparado para agir diante de diversas situações, dos vários gêneros textuais, dentro e fora dos muros da escola.

É relevante dizer que o homem existe como sujeito social a partir da linguagem, pois é por meio dela que ele apreende conceitos e valores culturais que possibilitam o entendimento do mundo, para que só então possa agir em busca de caminhos pessoais. Essa reflexão leva a uma compreensão maior do papel do professor em sala de aula. Há de se enfatizar o uso efetivo da língua, ajudar o aluno a se constituir como sujeito de direito, histórico e social, por meio do domínio da língua portuguesa, da interlocução em contextos e gêneros diversos, isto é, dentro de espaços e situações reais de produção linguística em oposição à mera decodificação, entendida agora, como o simples reconhecimento dos sinais impressos, sem a construção de um sentido maior para o texto (DELL'ISOLA, 2001). É em relação a isso que Foucambert (1994) defende que a leitura é uma atividade para os olhos e não para os ouvidos, querendo dizer com essa afirmação, que a leitura não se restringe ao aprendizado da correspondência fonema-grafema, mas que vai muito além, que o extrapola, na verdade.

Enfim, é papel da escola oferecer as ferramentas necessárias e dar também voz ao aluno para conscientizá-lo de que seu conhecimento de mundo e sua consciência são resultados desse processo dialógico, ou seja, desse processo de construção de sentido pela interlocução com o outrem através da linguagem. Nessa linha, segundo Mauro (1995, p. 28): 
[...] Em realidade, as formas linguísticas não têm qualquer capacidade semântica intrínseca: elas são instrumentos, expedientes, mais ou menos ingênuos, sem vida e sem valor fora das mãos dos homens, das comunidades históricas que as utilizam... O erro está na afirmação de que as palavras significam qualquer coisa: só os homens, ao contrário, significam, por meio de frases e palavras.

E para realizar tal empreitada, esse aluno necessita da ajuda do professor para que, como afirma Orlandi (1988, p. 80), "o aprendiz possa passar de enunciador a autor". Dessa maneira, entende-se que a escola, na figura do professor, deve permitir práticas que deem a esse jovem o controle dos mecanismos que deve usar no seu processo de leitura de hipertextos e consequente construção de significados. Ainda sobre esse aspecto da aprendizagem, isto é, a importância do papel do professor na formação da criança, Cedro, Moraes e Rosa (2010, p. 428) asseveram que:

\footnotetext{
Essa concepção de educação, a nosso ver, coloca um desafio para os profissionais envolvidos no processo de escolarização. Dentre eles, destacamos o professor, principal ator no cenário educativo, pois sua função primordial, ligada diretamente à dos estudantes, é a organização do ensino. Em outras palavras, cabe ao professor organizar o ensino tendo em vista que os conhecimentos elaborados historicamente pela humanidade, os conhecimentos das diferentes ciências, possam ser apropriados pelos indivíduos.
}

Enfim, ainda nessa perspectiva, o professor passa de mero transmissor das regras do código linguístico para mediador, para um coordenador do processo de apropriação da linguagem escrita por meio da apreensão de diversos elementos linguísticos inseridos nos textos e nas suas funções sociais. Deve-se destacar também que mediar e organizar esse processo não significa realizar as atividades pela criança, mas com ela. Desse modo, quando o aluno faz, com a ajuda do mestre, tarefas que superam seu nível de desenvolvimento, a criança se prepara para realizá-las sozinhas em outra situação, e assim o aprendizado cria processos de desenvolvimento que vão se consolidando e tornando-se parte de suas possibilidades reais.

Por fim, vale destacar mais uma vez que o professor é o maior responsável por permitir que o aluno, ao ler, também construa seu próprio texto, que seja autor, ainda que por meio de uma abordagem diferenciada, do uso consciente da linguagem por intermédio dos hipertextos no exercício de sua cidadania, porque "ler é o ponto de partida da ação" (BELLENGER, 1979, p. 10).

\section{CONSIDERAÇões FINAIS}

O momento em que se vive apresenta mudanças constantemente e esse fato, obviamente, afeta também a educação e os atores envolvidos no processo de ensino/aprendizagem, ou seja, o professor e seus alunos. No entanto, acreditamos que devemos tirar vantagem das TIC, de forma criativa e inteligente, para engajar os alunos com o objetivo 
de formar esses novos leitores como autores. A respeito dessa perspectiva das possíveis mudanças com a introdução das novas tecnologias no ensino, Tripathi (apud LEFFA, 2001, p. 212) afirma que:

\begin{abstract}
[...] o professor vai continuar dando sua aula, entretanto, poderá enriquecer o processo de ensino e de aprendizagem com todas as possibilidades que as tecnologias interativas proporcionam, como o uso da rede, mandar e receber mensagens dos alunos, criar listas de discussão (chats), monitorar as atividades através de um portal e fomentar debates com textos e páginas da Internet dentro e fora do horário regular de aulas.
\end{abstract}

Portanto, somente resta buscar estratégias que visem à conscientização do aluno pelo professor com práticas de leituras, de construção dos hipertextos ou de parte deles e ainda por meio de discussões acerca da aceitação ou não de certos caminhos escolhidos, realizando, assim, um processo de reflexão continuada para que o trabalho com a linguagem seja significativo para os alunos. Para isso, é preciso que o profissional de educação tenha clareza do sujeito que quer ajudar a formar, sem esquecer que suas concepções de sujeito estão diretamente ligadas à sua prática educativa.

Logo, não se pode esperar que os alunos aprendam a questionar ou a compreender as inferências num texto, ou em qualquer situação que envolva a linguagem, se isso não for uma prática constante no dia a dia da escola em todos os níveis de ensino, pois, aprende-se realmente pela discussão, pela reflexão sobre o conteúdo, enfim, pela construção conjunta de conhecimento mediada pela linguagem. A respeito dessa questão, Arena $(2009$, p. 2) afirma:

\footnotetext{
Práticas culturais de leitura de adultos, entre eles os professores, atualmente, orientam os alunos para a percepção de pistas sugeridas pelo título de um livro, pelo suporte material, pela configuração do texto, pelo contexto. Entre as práticas docentes, entretanto, há uma frequentemente desprezada: a de ensinar o leitor a elaborar perguntas que orientem sua ação de ler para encontrar ele próprio as respostas a essas perguntas, sempre efêmeras, precárias, substituíveis na medida em que prospera a atividade de ler.
}

$\mathrm{O}$ ato de ensinar impacta mais quando os alunos internalizam os processos desejados para depois incorporá-los as suas rotinas, isto é, o professor tem que achar formas de diminuir essa resistência aos atos de ler. E uma delas talvez seja o uso das TIC e a possibilidade de o aluno construir os seus próprios textos, os seus próprios caminhos por meio da reflexão conjunta acerca dos textos e dos caminhos a seguir na internet.

A questão fundamental não é a tecnológica. É necessário destacar que as TIC podem ajudar no ensino de língua portuguesa, mas, fundamentalmente, educar é ensinar os alunos a gerenciar um conjunto de informações e torná-las algo significativo para cada um deles, isto é, na forma de conhecimento adquirido que eles possam usá-lo durante e depois da escola.

No entanto, os professores têm também sido muito resistentes às mudanças, sempre acham desculpas para a inércia do sistema educativo caduco que está aí. Todavia, há uma 
verdade da qual não se pode fugir: A educação de todos esses jovens não pode ser mantida no total estado de monotonia e de asfixia criativa da atualidade. Em suma, o uso das TIC para complementar as aulas presenciais pode favorecer o ensino de língua portuguesa. Resta que sejam tomadas algumas providências para a sua implantação. Esses cuidados podem ser facilmente compensados pelas vantagens provenientes do uso de um ambiente virtual, quais sejam:

- $\quad$ prover os alunos com um suporte dentro e fora da sala de aula;

- aumentar a quantidade de insumo (textos nos seus mais diversos gêneros e nos mais diferentes sistemas sígnicos) recebida pelos alunos (XAVIER, 2004);

- usar inúmeras ferramentas (computador, tablet, celular etc.) presentes na realidade dos alunos para a aprendizagem de língua portuguesa; e, principalmente,

- possibilitar o aprimoramento das habilidades de leitura através de um processo de reflexão epilinguístico do hipertexto com o intuito final de formar cidadãos críticos e atuantes.

É essencial que o processo de ensino/aprendizagem destinado à formação do aluno produtor autônomo de seus textos se estabeleça num contexto interativo, dentro do qual o professor assuma o papel de estimular as trocas verbais entre todos os participantes e, com isso, proporcione as condições necessárias ao desenvolvimento dos conceitos necessários ao domínio cada vez mais amplo da tarefa de se formar autores não somente na sala de aula e, sim, indivíduos capazes de ler e autorar suas passagens no mundo, assegurando a participação do aluno como cidadão que deseja interferir de forma consciente na construção de sua história.

Enfim, é lamentável que a escola deixou de ser o lugar onde as pessoas se apaixonavam pela língua, por seus usos, por seus torneios, segredos e mistérios (ANTUNES, 2007). O ensino da linguagem reduziu-se simplesmente à utilidade das nomenclaturas, do estudo sintático e das classificações. Porém, o uso das TIC, com sua vasta intertextualidade e dialogia semiótica, consideradas as devidas adequações, pode ajudar a reverter essa constatação.

\section{REFERÊNCIAS}

ANTUNES, Irandé. Muito além da gramática: por um ensino de línguas sem pedras no caminho, São Paulo: Parábola editorial, 2007.

ARENA, Dagoberto Buim. Situação de leitura em classe de $3^{\text {a }}$ série, 2009. Disponível em: $<$ http://alb.com.br/arquivo-porto/edicoes_anteriores/anais17/txtcompletos/sem13/ COLE_203.pdf $>$. Acesso em: 19 jan., 2015.

BARTHES, Roland. O Prazer do Texto, São Paulo: Perspectiva, 2006.

BELLENGER, Lionel. Os Métodos de Leitura, Rio de Janeiro: Zahar Editores, 1979. 
BRASIL. Secretaria de Educação. Parâmetros Curriculares Nacionais: Ensino Fundamental e Médio, Brasília: MEC, 2002.

BREVES, José. Filho. Uma leitura da literatura infantil na escola, Fortaleza: Editora Breves Palavras, 2004.

BRIGGS, Asa; BURKE, Peter. Uma história social da mídia: de Gutenberg à Internet. Trad. Maria Carmelita Pádua Dias, Rio de Janeiro: Jorge Zahar, 2004.

CEDRO, Wellington Lima; MORAES, Silvia Pereira Gonzaga e ROSA, Euzébio Josélia. A atividade de ensino e o desenvolvimento do pensamento teórico em matemática. Ciênc. educ. (Bauru), vol. 16, no. 2, Bauru, 2010. Disponível em: $<$ http://dx.doi.org/10.1590/ S1516-73132010000200011>. Acesso em: 13 jan., 2015.

DELL'ISOLA, Regina Lúcia Péret. Leitura: inferências e o contexto sociocultural, Belo Horizonte: Formato Editorial, 2001.

DONATO, Richard. Collective scaffolding in language learning. In: LANTOLF, J.; APPEL, G. (Orgs.). Vygostskian approaches to second language research, New Jersey; Ablex Publishing Corporation, 1994, p. 33-56.

FOUCAMBERT, Jean. A leitura em questão, Porto Alegre: Artes Médicas, 1994.

FOUCAULT, Michel. O que é um autor? Trad. Antônio F. Cascais e Edmundo Cordeiro, Veja, Lisboa: Passagem, 1992.

IBOPE MEDIA. Dados da Internet no Brasil em 2015, 2016. Disponível em: <info. abril.com.br/noticias/tecnologia-pessoal/2013/10/ibope-aponta-que-acesso-a- Internet-cresce-3-no-2-trimestre.shtml>. Acesso em: 14 nov., 2016.

KOMESU, F. Pensar em Hipertexto. In: ARAÚJO, J.; BIASI-RODRIGUES, B. Interação e Internet: novas formas de usar a linguagem, Rio de Janeiro: Lucerna, 2005.

MAGNABOSCO, Gislaine Gracia. Hipertexto e gêneros digitais: modificações no ler e escrever? Conjectura, vol. 14, n. 2, mai./ago., 2009, p. 49-63.

MAURO, Tullio de. "Notas." In: SAUSSURE, F. Cours de linguistique générale, 4. ed., Paris: Payot, 1995.

MILLER, Stela. Sem reflexão não há solução: o desenvolvimento do aluno como autor autônomo de textos escritos. In: MORTATI, M. do R. Atuação de professores: propostas para a ação reflexiva no ensino fundamental, 1. ed., Araraquara, JM Editora, 2003, p. 9-22.

ORLANDI, Eni Puccinelli. Discurso e leitura, São Paulo: Cortez; Campinas, SP: Editora da Universidade de Campinas, 1988. (Nem escritor, nem sujeito, apenas autor; Significação, leitura e redação, p. 75-94.)

PALLOF, Richard \& PRATT, Keith. Building learning communities in ciberspace, California: Jossey Bass Inc. Publishers, 1999. 
PARÂMETOS curriculares nacionais de língua portuguesa. Terceiro e quarto ciclos do ensino fundamental. Disponível em: <http://mecsrv04mec.gov.br/sef/estrut2/pen/pdf/ portugues.pdf>. Acesso em: 20 jul., 2014.

PERRENOUD, Philippe. Dez novas competências para ensinar, Porto Alegre: Artes Médicas, 2000.

PLATÃO, Francisco e FIORIN, José Luís. Para entender o texto, São Paulo: Ática, 1990.

TELES, Giovana. MEC divulga notas do ENEM: mais de 500 mil tiraram nota zero na redação. Globo.com. 2015. Disponível em: <http://g1.globo.com/jornal-da-globo/noticia/2015/01/mec-divulga-notas-do-enem-mais-de-500-mil-tiraram-nota-zero-na-redacao. html>. Acesso em: 16 jan., 2015.

TRIPATHI, Anil Kumar. Implications of Internet learning. ON LINE - ED Newsletter, 01/06/1999.

UOL EDUCAÇÃO. Pisa: desempenho do Brasil piora em leitura e 'empaca' em ciências, 2014. Disponível em: <http://educacao.uol.com.br/noticias/2013/12/03/pisa-desempenho-do-brasil-piora-em-leitura-e-empaca-em-ciencias.htm>. Acesso em: 18 jan., 2015.

WARSCHAUER, Mark \& KERN, Richard. Network based language teaching, Cambridge: Cambridge University Press, 2000, p. 59-86.

XAVIER, Antônio Carlos. Leitura, texto e hipertexto. In: MARCUSCHI, Luiz Antônio \& XAVIER, A. C. (Orgs.). Hipertexto e gêneros digitais: novas formas de construção de sentido, Rio de Janeiro: Lucerna, 2004, p. 170-180.

\section{Dados dos Autores}

JEAn Custódio de Lima

Doutorando em Educação pela Universidade Estadual Paulista. Professor de Português/ Inglês do Departamento de Licenciatura do Instituto Federal do Ceará. Limoeiro do Norte/CE - Brasil. jeanclima@terra.com.br

\section{Dagoberto Buim Arena}

Doutor em Educação pela Universidade Estadual Paulista. Professor Adjunto do Departamento de Didática e do Programa de Pós-Graduação em Educação da Universidade Estadual Paulista. Marília/SP - Brasil. dagobertobuim@gmail.com

Submetido em: 26-8-2015

Aceito em: 9-2-2017 